\title{
PRAEFA TIO.
}

C

um divendita esse accepissem exempla editionis Bucolicorum graecorum ante hos tredecim annos a me curatae, denuo animum ad illa carmina recognoscenda applicui : qua in re quam rationem sequutus sim paucis exponam. Novorum subsidiorum cum nihil mili suppeteret atque in Gaisfordianis opibus acquiescendum esset, his ita usus sum ut, cum textum exhibuerim Valckenarianum a Gaisfordio modeste correctum, plurimis tamen locis aliam lectionem repraesentarim. id ubicunque factum est, si leviora excipias, in margine indicatum reperies. Contra codicum vel vetustissimarum editionum auctoritatem quidquid sive ab aliis sive a me ipso novatum est, in adnotationibus monendum duxi; qua in re non mirabor tamen si quando minus diligens fuisse deprehendar, id quod accidit mihi Theocr. Idyll. IV. 51. ubi non monito lectore $F$ alckenburgium sequutus

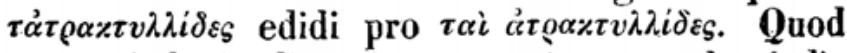
corruptis locis aliquoties apposui corruptelae indicium (*) multo pluribus locis apponendum fuisse haud infitior: sunt enim depravatissina haec earmina multoque graviores corruptelas subiisse videntur quam plerique editores suspicati sunt. In 
commenorandis criticorum coniecturis quod severum habui delectum, nolo equidem ita accipi ac si nihil eorum quae silentio praetermisi probandum existimem; atque omnino meminisse velim lectores non iustam me exhibere voluisse editionem, sed quae Gaisfordianae quasi supplementum haberi posset. 'Theodori Bergkii, felicissimi coniectoris, emendationes petii ex Diurnis scholasticis eiusque ad Anacreontem adnotationibus; alias ipse mecum vir doctissimus communicavit per epistolam. Thomae Briggsii coniectanea suppeditavit Gaisfordii poetarum minorum volumen secundum et quartum :- ipsam enim, quam illum parasse audio, editionem inspicere non licuit. De dialecto, qua usi sunt poetae bucolici, disputare non supersedissem equidem, nisi totam hanc rem in ampliore, quam paraturus sum, horum poetarum editione accuratius tractare mili proposuissenn: vix enim certo pede in hac quaestione procedere licebit, nisi antea melioris notae codices accuratius quam adhuc factum est excussi fuerint. Interim hanc legem, quamquam non constanter, sequutus sum, ut quos dorismos interpretes contra librorum fidem his carminibus intulissent, rursus expellerem.

Quod coniunctim edi solet cum Theocriteis carmen Anacreonticis versibus scriptum in Adonidem, quum manifesta inferiors aetatis indicia habeat, repetere nolui: ac magnopere vellem etiam alia quaedam aut plane reccidissem a Theocriteis aut incerto auctori assignassem. In his numero idyllia quae inter Theocritea le- 
ountur, undevicesimum, vicesimum et vicesimum septimum: quorum quae primo et postremo loco commemoravi, neminem hodie adeo invenustum et Theocriteae rationis imperitum esse credo, quin ea a Theocrito abiudicanda esse persuasum habeat. Minus de vicesimo Idyllio sive Bovxohioxw constare video, quod carmen quum Jo. Toupius satis futili argumento usus (v. Valcken.) Theocrito ereptum iverit, alias afferre iuvat rationes, quibus controversia dirimi posse videtur. Nihil nune dicam de argumento carminis, cuius ea est simplicitas quae a Theocriti subrustica suavitate aliquantum abhorreat; nihil de manifesta aliorum Theocriti locorum imitatione, cuius luculenta aliquot exempla attulerunt interpretes: graviora, ut milhi quidem videtur, argumenta ex orationis indole peti possunt, cuius ea est ratio, ut Moschum potius vel Bionem quam Theocritum carminis auctorem esse appareat. Ita quam vs. 19 et 32 et apud Bionem I. 53 habemus formam doricam $\grave{c} \mu \mu i$, ea nunquam usus est Theocritus, quod fugit Brunckium, qui XVIII.

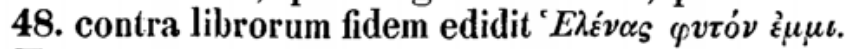
Tum constanter abstinuit Theocritus in bucolicis carminibus correptione syllabae ante $\beta \lambda$ vel $\gamma \lambda$, qua bis usus est Bov\%ohiб\%ov scriptor vs. 6. oía $\beta \lambda \dot{\varepsilon} \pi \varepsilon \iota_{\mathrm{S}}$ et vs. 13. $о \mu \mu \alpha \sigma \iota ~ \lambda o \xi \dot{\alpha} \beta \lambda \dot{\varepsilon} \pi \circ \iota \sigma$. Idem fecit Bio III.

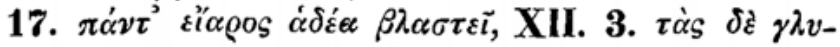

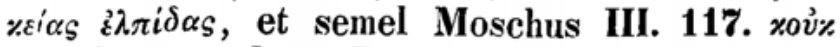
$\dot{\varepsilon} \gamma \lambda v * \alpha \dot{\alpha} \nu \vartheta \eta$. quod enim II. 74. legebatur $\varepsilon^{\prime} \beta \dot{\varepsilon} \beta \lambda \eta \tau$ nunc

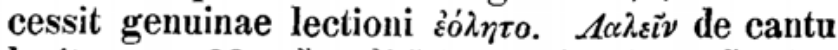

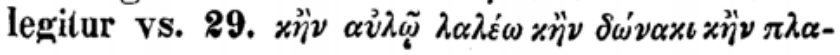


gıai $\lambda \omega$, contra usum Theocriti (nam V. 34. huc non pertinet), non item Moschi, cuius vide III. 48 et 113. Praeterea ad haec velim attendas. xṕryos, quo vocabulo optimi quique scriptores (v. Buttmanni Lexil. I. p. 25.) atque in his ipse

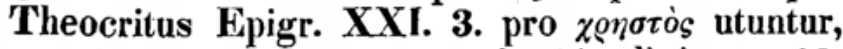
nostri carminis auctor pro $\left.\alpha^{3} \lambda \eta \vartheta \dot{\eta}\right\rangle$ dixit vs. 19.

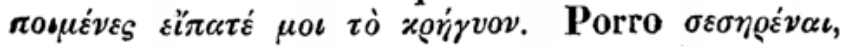
quod Theocritus de libidinoso et suavi risu dixit V. 116 et VII. 19, in nostro carmine contraria significatione legitur de risu contumeliae

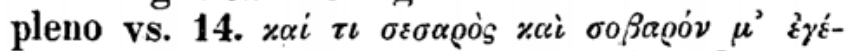
$\lambda \alpha \xi \varepsilon$. Denique ne illud quidem negligendum est, ad quod non attendit Valckenarius ad Idyll. 1 . 35, nunquam Theocritum ultimam syllabam do-

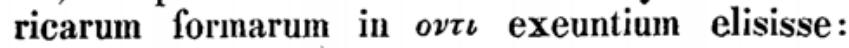

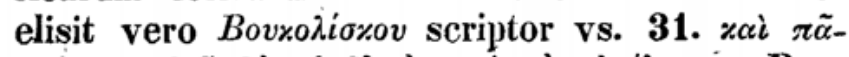

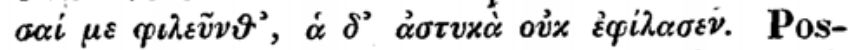
sem alia addere; sed haec speciminis loco sufficiant.

Scribebam Berolini Cal. Mai. a. MDcccxxxvı. 